\title{
Reversible Thiazolidine Exchange: A New Reaction Suitable for Dynamic Combinatorial Chemistry
}

\author{
Cecilia Saiz, Peter Wipf, Eduardo Manta, and Graciela Mahler ${ }^{\star}$ \\ Laboratorio de Química Farmacéutica, DQO, Facultad de Química, Universidad de la República, \\ CC 115, Montevideo, Uruguay, and Department of Chemistry, University of Pittsburgh, Pittsburgh, \\ PA, 15260, USA
}

\section{Abstract<smiles>[B]C1NC(C(=O)OCC)CS1</smiles><smiles>O=C[C@H]1CO[C@@H]2CO[C@@H]1C2</smiles><smiles>CCOC(=O)C1CSC([18O])N1</smiles><smiles>[R]C1SC[C@@H]2COC([10BH2])N12</smiles> $\mathrm{pH} 4$, rt, 2 days<smiles>C[C@H](C=O)C(C=O)C=O</smiles> $\mathrm{CH}_{2} \mathrm{Cl}_{2}, p-\mathrm{TsOH}, \quad \mathbf{R}^{1}$<smiles>[2H][C@@H]1SC[C@H]2CO[13CH2]N12</smiles> rt, 2 days}

New dynamic combinatorial libraries (DCLs) were generated using the reversible aminothiol exchange reaction of thiazolidines and aromatic aldehydes. The reaction proceeded in aqueous buffered media at $\mathrm{pH} 4$ and room temperature to generate thermodynamically controlled mixtures of heterocycles. The synthesis of an enantiomerically pure thiazolidinyloxazolidine is also reported. The oxazolidine moiety could be exchanged in $\mathrm{CH}_{2} \mathrm{Cl}_{2}$ in the presence of catalytic $p$ - $\mathrm{TsOH}$.

Dynamic combinatorial chemistry (DCC) has considerable potential in the discovery of small molecule ligands for artificial receptors and large biomolecules. DCC is largely based on the use of reversible reactions to generate compound mixtures - Dynamic Combinatorial Libraries (DCLs) - that are in thermodynamic equilibrium. The composition of the library is determined by the properties of each of the library members under the particular conditions of the experiment; this equilibrium is likely to respond to the presence of a template or another change in the environment. ${ }^{1}$

The covalent reversible reactions usable in DCC are relatively rare compared to the irreversible processes favored in traditional synthetic chemistry, and most of the former involve carbonyl compounds, imines and acetals.

Four different types of substrates have previously been used to generate DCLs from carbonyl compounds by acetal exchange (Figure 1): a) diols in the presence of catalytic $\mathrm{TfOH}^{2}$ $\mathrm{H}_{2} \mathrm{SO}_{4}, 3$ or $p-\mathrm{TsOH} ;{ }^{4}$ b) aminoalcohols, leading to mixtures of imines, oxazinanes and oxazolines; $\left.{ }^{5} \mathrm{c}\right)$ thiols in the presence of catalytic $\mathrm{Zn}(\mathrm{OTf})_{2}, 6 \mathrm{a}$ or $\mathrm{Hf}(\mathrm{OTf})_{4} ; 6 \mathrm{~b}$ and d) diamines in aqueous buffered media at $\mathrm{pH} \mathrm{4}$, conditions described by our group for the formation of pyrazolotriazinone heterocycles. ${ }^{7}$

gmahler@fq.edu.uy.

Supporting Information Available: Experimental procedures, ${ }^{1} \mathrm{H}$ NMR and HPLC of DCLs, and spectral data for compounds $\mathbf{4 b}, \mathbf{5 b}$, 6aa, 6ab, 6ba, and $\mathbf{6 b b}$. This material is available free of charge via the Internet at http://pubs.acs.org. 
The acid-catalyzed transacetylation of thiazolidines and related compounds attracted our closer attention as a possible extension of the latter heterocycle formation process.

Thiazolidines $\mathbf{3}$ were selected as simple models in order to identify equilibration conditions for DCL formation. In spite of a literature report on the reversible formation of thiazolidines under basic conditions, ${ }^{8}$ this transformation has not been previously reported as useful for DCC. 4-Carboxyl ethyl-2-arylthiazolidines can be readily obtained by condensation of aldehydes (1) and cysteine ethyl ester (2) in EtOH at room temperature (Scheme 1).

The discovery of new reversible reactions compatible with an aqueous enviroment is an important objective for the use of biomolecules as templates in DCLs. We screened different aqueous conditions, with variations in $\mathrm{pH}$ and reaction time, in order to establish optimal thermodynamic exchange conditions for the thiazolidine exchange. The reaction of $\mathbf{3 a}$ with equimolar amounts of $p$-Cl-benzaldehyde (1b) at room temperature was used as a reference (Table 1).

Thermodynamic equilibration of a mixture of $\mathbf{3 a}$ and $\mathbf{1 b}$ occurred at $\mathrm{pH} 4$ over 24 to $48 \mathrm{~h}$ at room temperature. ${ }^{9}$ After $3 \mathrm{~d}$, heterocycles $\mathbf{3 a}$ and $\mathbf{3 b}$ were stable in the aqueous environment and thiazolidines (90-98\%) and ester $2(2-10 \%)$ were recovered (entries 1, 2 and 3).

Equilibration at $\mathrm{pH} 5$ was slower, but after $3 \mathrm{~d}$, the ratio indicated that equilibrium was reached (entries 4, 5 and 6). Equilibration at pH 6 was not complete after $3 \mathrm{~d}$ at $\mathrm{rt}$ (entries 7, 8 and 9). Equilibration at $\mathrm{pH} 7 \mathrm{did}$ not proceed during $3 \mathrm{~d}$ at $\mathrm{rt}$ (entry 10) and the presence of ester 2 was not detected. The method of choice for blocking further equilibration is a simple raise of $\mathrm{pH}$ to 7 ; since we did not observe any further equilibration at this $\mathrm{pH}$, the yields of recovered products were quantitative.

When the temperature was increased to $35^{\circ} \mathrm{C}$ at $\mathrm{pH} 4$, the equilibration ocurred faster, but significant amounts of cysteine ester $\mathbf{2}$ were observed. The total recovered yield for thiazolidines was $64 \%$ and $49 \%$ after $1 \mathrm{~d}$ and $2 \mathrm{~d}$, respectively (Table 1, entries 11 and 12). The mass balance was decreasing, probably due to ester hydrolysis in compound $\mathbf{2}$.

Thiazolidines $\mathbf{3 a}$ and $\mathbf{3 b}$ have different stabilities depending on $\mathrm{pH}$; at $\mathrm{pH} 4-5$ thiazolidine hydrolysis occurs to an acceptable extent (2-10\%) at rt over $3 \mathrm{~d}$. Temperature seems to play an important role in these systems; higher temperatures accelerate the exchange process but under concomitant hydrolysis of the thiazolidine and the cysteine ethyl ester.

We also probed the reversibility of the system by starting from products $\mathbf{3 b}$ and $\mathbf{3 c}$ at $\mathrm{pH} 4$ (Table 2). If equilibration was reached, the distribution pattern should be identical. At $\mathrm{pH} 4$, equilibration required $48 \mathrm{~h}$ at rt, providing a comparable product ratio as observed for the inverse process (entries 1 and 2, Table 2)

Thiazolidine 3a with aldehydes $\mathbf{1 b}$ and $\mathbf{1 d - f}$ were allowed to equilibrate, the starting concentrations of the mixture components were kept at $1 \mathrm{mM}$ each. The distribution of the corresponding heterocycles varied slightly for thiazolidines 3a,b,e and f $\mathbf{f}(20-24 \%)$ except for 3d $(11 \%)$ after $2 \mathrm{~d}$. Thiazolidine 3d bearing an EDG on the benzene ring has the lowest stability in the acidic medium. The mass balance indicated a $93 \%$ yield of thiazolidines and $7 \%$ of ester 2 after $4 \mathrm{~d}$, and the distribution remained unchanged. Even though some formation of compound 2 was observed, thiazolidines are stable in the acid media $(\mathrm{pH} 4)$ for $4 \mathrm{~d}$. This stability enables this DCL for the observation of template effects.

We also studied the possibility for direct side-chain metathesis of thiazolidines. An equimolecular mixture of $\mathbf{3 a}$ and $\mathbf{4 b}$, which differ by their substitution at 2, 4 and 5-positions of the heterocycles, was equilibrated during $2 \mathrm{~d}$ at $\mathrm{pH} 4$ and $\mathrm{rt}$ (Scheme 3). As expected, a mixture of four products (the original starting materials and two crossover derivatives) was 
formed. Small amounts of penicillamine methyl ester (3\%) and cysteine ethyl ester (7\%) were also detected, but $90 \%$ of the thiazolidine products was recovered after $3 \mathrm{~d}$.

As a means to increase diversity in the side chains at the 4-position of the heterocycles, the ester moiety of thiazolidines 3a-b was converted to the alcohol by reduction with $\mathrm{NaBH}_{4}$. When the aminoalcohols $\mathbf{5 a}-\mathbf{b}$ were treated with aldehydes $\mathbf{1 a}-\mathbf{b}$ in acid media $(p-\mathrm{TsOH})$, the fused thiazolidine-oxazolidines $\mathbf{6}$ were formed. This class of compounds represents a new example of a bicyclic DCC scaffold (Scheme 4). ${ }^{10}$ Even though aminoalcohols 5 were used as a 1:1 mixture of diastereomers, only anti-6 was formed. The relative configuration was confirmed by NOE experiments. This result is not completely unexpected due to the fact that thiazolidines undergo facile ring opening and closure reactions. ${ }^{11}$

We hypothesize that this reaction proceeds by a thermodynamic equilibration, with anti-6 being the more stable fused heterocycle.

Thiazolidinyloxazolidine heterocycles present interesting opportunities for exchange processes: products include thiazolidine $\mathbf{5}_{\mathbf{R}}$, oxazolidine $\mathbf{8}_{\mathbf{R}}$, the fused heterocycles at the thiazolidine or the oxazolidine site $\mathbf{6}_{\mathbf{R} R}$ and also the imine isomers $\mathbf{9}_{\mathbf{R}},{ }^{12}$ as shown in Scheme 5 .

When bicycle 6aa [10 $\mathrm{mM}$ ] in $\mathrm{CH}_{2} \mathrm{Cl}_{2}$ was equilibrated at $\mathrm{rt}$ with an equimolar amount of aldehyde $\mathbf{1 b}$ in the presence of catalytic $p$-TsOH, only the mixture of the exchanged products 6aa and $6 \mathbf{a b}$ and free aminoalcohol $5 \mathbf{a}$ was obtained (Scheme 6). ${ }^{13}$ In order to identify the products, it was necessary to perform a chiral-HPLC (Chiralcel-OD) analysis of the possible products $6 \mathbf{b a}$ and $\mathbf{6 a b}$, because they have almost identical signals in the ${ }^{1} \mathrm{H}$ NMR spectra. The chromatographic analysis indicated that the exchange was limited to the N-C-O linkage, forming $6 \mathbf{a b}$. Alternative species like imines $9 \mathbf{a}, 9 \mathbf{b}$ or oxazolidines $8 \mathbf{a}, 8 \mathbf{b}$ were not detected in the ${ }^{1} \mathrm{H}$ NMR spectra or the HPLC traces.

We also performed an experiment in absence of $p$ - $\mathrm{TsOH}$ in $\mathrm{CDCl}_{3}$ with compound $6 \mathbf{a a}$ and aldehyde $\mathbf{1 b}$ at a $10 \mathrm{mM}$ concentration, and we found no evidence of exchange or decomposition after $3 \mathrm{~d}$. This observation is indicative that the products are stable and that the exchange requires acid catalysis.

It is important to point out that conditions for the synthesis and exchange of these bicycles are quite similar, i.e. $\mathrm{CH}_{2} \mathrm{Cl}_{2}$ and $p$-TsOH. In the acidic media, the diasteromeric mixture of alcohol $\mathbf{5}$ is in a fast equilibration by ring opening and closing. During this equilibration only the acetal $\mathrm{N}-\mathrm{C}$ bond of thiazolidine would be broken and the $\mathrm{R}^{1}$ side chain remains linked to the sulfur atom, probably via a sulfenium cation. This mechanism explains that we did not observe the formation of $\mathbf{6}_{\mathbf{R} 2 \mathbf{R} 1}$ in the synthesis of $\mathbf{6}_{\mathbf{R} 1 \mathbf{R} 2}$ and also why the exchange occcurred only at the oxazolidine site.

In summary, we explored a new exchange reaction between thiazolidines and carbonyl compounds. The thermodynamic exchange proceeds in an acidic aqueous environment $(\mathrm{pH} 4)$ and represents a new reversible reaction useful for DCC methodologies. A structural diversification of the core scaffolds can be accomplished by modifications at the 5- and 4positions of the heterocycles. The thiazolidines $\mathbf{3 a - f}$ are stable in buffered media over $4 \mathrm{~d}$, and these conditions are suitable for the generation of DCLs as well as for the direct screening of these libraries. Moreover, the exchange reaction can be stopped by raising the $\mathrm{pH}$ to 7 , thus providing a convenient way to analyze the compound distribution patterns. As an important extension of this work, we also present the synthesis of fused thiazolidine-oxazolidine heterocycles such as anti-6, representing a new compound class. These bicycles are stable under neutral or basic conditions but can be equilibrated at the oxazolidine moiety in $\mathrm{CH}_{2} \mathrm{Cl}_{2}$ in the presence of catalytic $p-\mathrm{TsOH}$. 


\section{Supplementary Material}

Refer to Web version on PubMed Central for supplementary material.

\section{Acknowledgment}

This work was supported by the National Institutes of Health-FIRCA (R03TW007772), and NIH CA078039. C.S. thanks UdelaR (CSIC-N ${ }^{\circ} 349$ ). We would like to thank H. Pezzaroglo of Nuclear Magnetic Resonance Laboratory, UdelaR for NMR spectra.

\section{References}

1. For reviews, see: (a)Ladame S. Org. Biomol. Chem 2008;6:219-226.226 [PubMed: 18174988] (b) Ludlow RF, Otto S. Chem. Soc. Rev 2008;37:101-108.108 [PubMed: 18197336] (c)Lehn J-M. Chem. Soc. Rev 2007;36:151-160.160 [PubMed: 17264919] (d)Corbett PT, Leclaire J, Vial L, West KR, Wietor J-L, Sanders JKM, Otto S. Chem. Rev 2006;106:3652-3711.3711 [PubMed: 16967917]

2. (a) Cacciapaglia R, Di Stefano S, Mandolini L. J. Am. Chem. Soc 2005;127:13666-13671. [PubMed: 16190732] (b) Fuchs B, Nelson A, Star A, Stoddart JF, Vidal S. Angew. Chem. Int. Ed. Engl 2003;42:4220-4224. [PubMed: 14502741] (c) Cacciapaglia R, Di Stefano S, Mandolini L, Mencarelli P, Ugozzoli F. Eur. J. Org. Chem 2008:186-195.

3. Berkovich-Berger D, Lemcoff NG. Chem. Commun 2008:1686-1688.

4. Lemcoff NG, Fuchs B. Org. Lett 2002;4:731-734. [PubMed: 11869113]

5. (a) Star A, Goldberg I, Fuchs B. Angew. Chem., Int. Ed 2000;39:2685-2689. (b) Star A, Goldberg I, Fuchs B. J. Organomet. Chem 2001;630:67-77.

6. (a) Sutton LR, Donaubauer WA, Hampel F, Hirsch A. Chem. Commun 2004:1758-1759. (b) Wu YC, Zhu J. J. Org. Chem 2008;73:9522-9524.

7. Wipf P, Mahler SG, Okumura K. Org. Lett 2005;7:4483-4486. [PubMed: 16178564]

8. (a) Woodward GE, Schroeder EF. J. Am. Chem. Soc 1937;59:1690-1694. (b) Szilagyi L, Gyorgydeak Z. J. Am. Chem. Soc 1979;101:427-432.

9. Typical procedure. A solution of compound 3a $(20.8 \mathrm{mg}, 0.09 \mathrm{mmol})$ and $p$-Cl-benzaldehyde (12.3 $\mathrm{mg}, 0.09 \mathrm{mmol})$ in a mixture of acetate buffer at $\mathrm{pH} 4(63 \mathrm{~mL})$ and $\mathrm{MeOH}(27 \mathrm{~mL})$ was stirred at $\mathrm{rt}$ for $2 \mathrm{~d}$. The $\mathrm{pH}$ was raised to 7 by adding a saturated solution of $\mathrm{NaHCO}_{3}$ and the reaction mixture was extracted with $\mathrm{CH}_{2} \mathrm{Cl}_{2}$. The combined organic layers were dried $\left(\mathrm{MgSO}_{4}\right)$, filtered and concentrated in vacuo (temperature should never exceed $22{ }^{\circ} \mathrm{C}$ ). The residue was analyzed by ${ }^{1} \mathrm{H} \mathrm{NMR}$ to determine the ratio and products were confirmed by preparative isolation of $\mathbf{3 a}+\mathbf{3 b}(26 \mathrm{mg}, 98 \%$ yield).

10. Related fused thiazolidine-oxazolidinones and thiazolidine-oxazolidines were obtained when aminoalcohol 5a was treated with phosgene: González A, Lavilla R, Piniella JF, Alvarez-Larena A. Tetrahedron 1995;51:3015-3024.3024

11. Deroose FD, De Clercq PJ. J. Org. Chem 1995;60:321-330.330 and ref 8b

12. In ref 5a, Fuchs and coworkers report traces of imine in a DCL constructed from aminoalcohols.

13. Typical procedure. A mixture of compound 6aa (100 mg, $0.36 \mathrm{mmol})$ and $p$-Cl-benzaldehyde (50 $\mathrm{mg}, 0.36 \mathrm{mmol})$ in $\mathrm{CH}_{2} \mathrm{Cl}_{2}(35.5 \mathrm{~mL})$ and $p$-toluenesulfonic acid $(10 \mathrm{mg}, 0.13 \mathrm{mmol})$ was stirred at $\mathrm{rt}$ for $2 \mathrm{~d}$. The reaction mixture was poured into water, the $\mathrm{pH}$ adjusted to $\mathrm{pH} 7$ and the mixture was extracted with $\mathrm{CH}_{2} \mathrm{Cl}_{2}(3 \times 30 \mathrm{~mL})$. The organic layers were dried, filtered and solvent was removed under reduced pressure. The residue was analyzed by ${ }^{1} \mathrm{H}$ NMR to determine the product ratio and the products were confirmed by preparative isolation. 

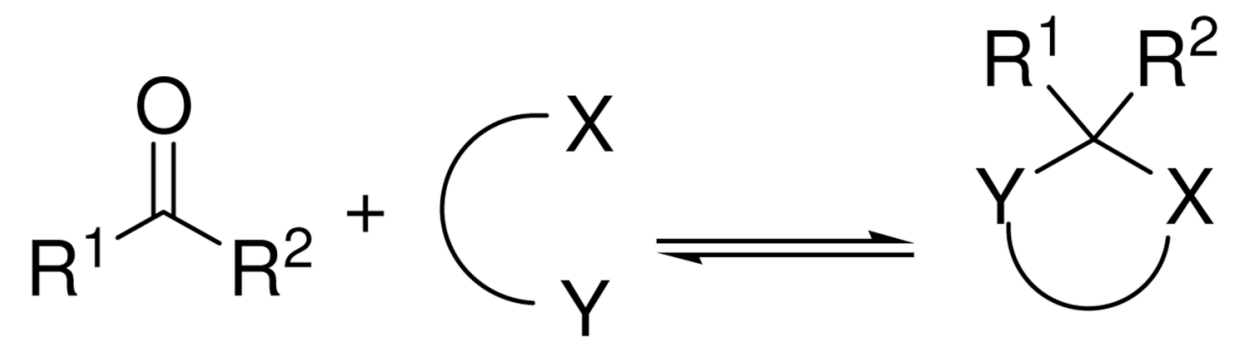

a) $X=Y=O$
b) $X=O, Y=N$
c) $X=Y=S$
d) $X=Y=N$

Figure 1.

Cyclic acetal formations suitable for DCL. 

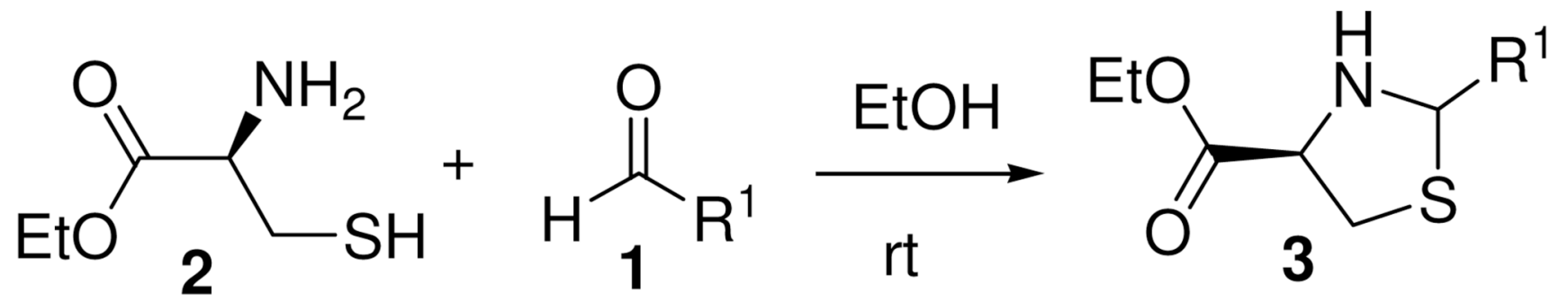

Scheme 1.

Thiazolidine formation from cysteine 


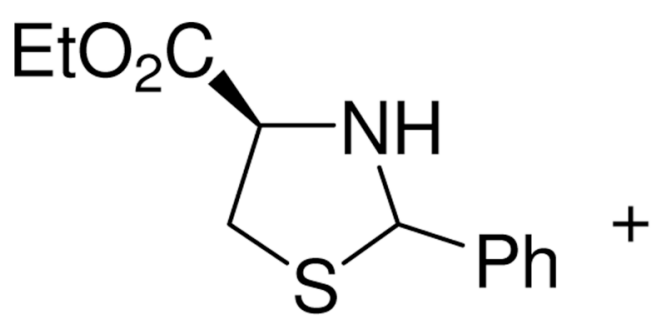

3a $\underset{\mathbf{1} \mathbf{b}}{p-\mathrm{CIPhCHO}}+\underset{\mathbf{1 d}}{p-\mathrm{OMePhCHO}}$

p-MePhCHO $1 e$

$m-\mathrm{MePhCHO}$

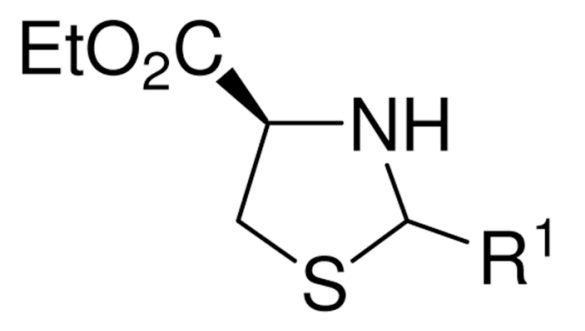

$\mathrm{pH} 4, \mathrm{rt}$
$2 \mathrm{~d},[1 \mathrm{mM}]$

3a; $\mathrm{R}^{1}=\mathrm{Ph}(21 \%)$

3b; $\mathrm{R}^{1}=p$-CIPh (20\%)

3d; $\mathrm{R}^{1}=p$-OMePh (11\%)

$3 e ; \mathrm{R}^{1}=p-\mathrm{MePh}(24 \%)$

3f; $\mathrm{R}^{1}=m-\mathrm{MePh}(24 \%)$

Scheme 2.

Exchange reaction between thiazolidines $\mathbf{3 a}$ and aldehydes $\mathbf{1 b}, \mathbf{1 d - f . a}$

a The yields in parentheses reflect the equilibrium distribution. The ratio was determined by ${ }^{1} \mathrm{H}$ NMR and confirmed by preparative isolation. 


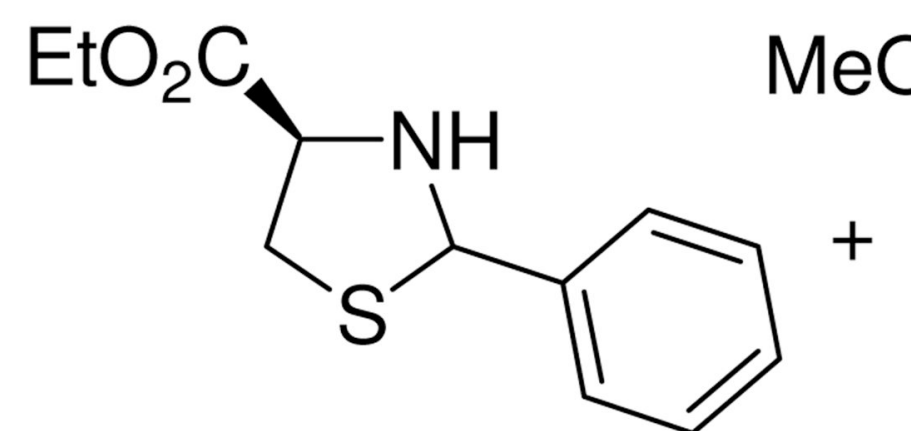

$3 a(36 \%)$
$\mathrm{EtO}_{2} \mathrm{C}$
$3 b(12 \%)$
$\mathrm{pH} 4, \mathrm{rt}$

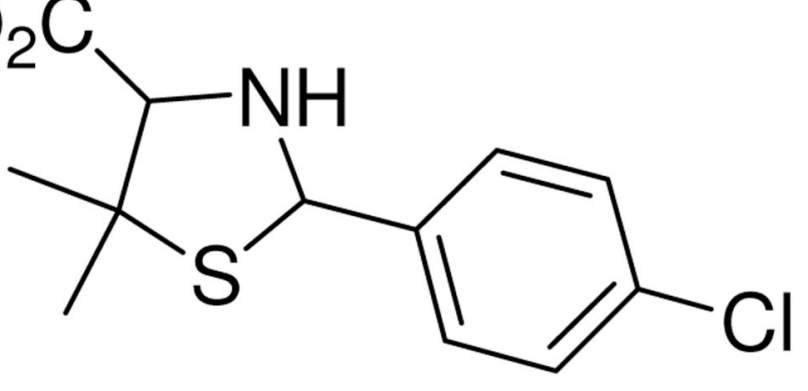

$2 \mathrm{~d},[1 \mathrm{mM}]$

$4 b(30 \%)$

Scheme 3.

Metathesis of thiazolidines.a

a The yields in parentheses reflect the equilibrium distribution. The ratio was determined by ${ }^{1} \mathrm{H}$ NMR and confirmed by preparative isolation. 
<smiles>[R]C1N[C@H](C(=O)O[Ga])CS1</smiles>

$3 a R^{1}=P h$

3b $\mathrm{R}^{1}=p-\mathrm{Cl} \mathrm{Ph}$

$\underset{p-\mathrm{TsOH}}{\stackrel{\mathrm{CH}_{2} \mathrm{Cl}_{2}, \mathrm{rt}}{\longrightarrow}}$ $\mathrm{R}^{2} \mathrm{CHO}$

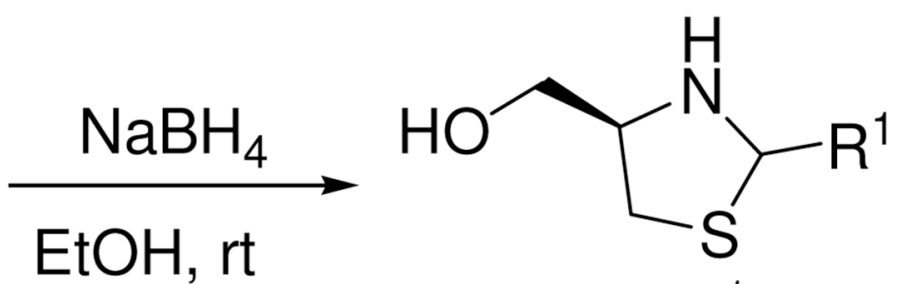

5 a $(70 \%), \mathrm{R}^{1}=\mathrm{Ph}$ 5b $(65 \%), \mathrm{R}^{1}=p-\mathrm{Cl} \mathrm{Ph}$

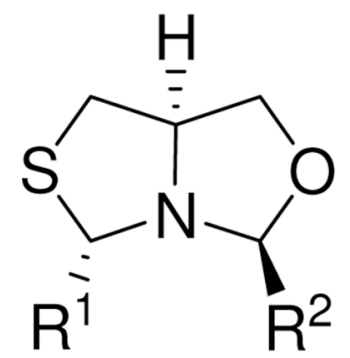

6aa $\left(75 \%, 99.9 \%\right.$ de); $R^{1}=P h, R^{2}=P h$ 6ab $\left(80 \%, 85.2 \%\right.$ de); $\mathrm{R}^{1}=\mathrm{Ph}, \mathrm{R}^{2}=p-\mathrm{Cl}-\mathrm{Ph}$ 6ba $\left(94 \%, 89.7 \%\right.$ de); $\mathrm{R}^{1}=p-\mathrm{Cl}-\mathrm{Ph}, \mathrm{R}^{2}=\mathrm{Ph}$ 6 bb $\left(60 \%, 99.9 \%\right.$ de); $\mathrm{R}^{1}=p-\mathrm{Cl}-\mathrm{Ph}, \mathrm{R}^{2}=p-\mathrm{Cl}-\mathrm{Ph}$

Scheme 4.

Synthesis of fused thiazolidine-oxazolidine heterocycles. 


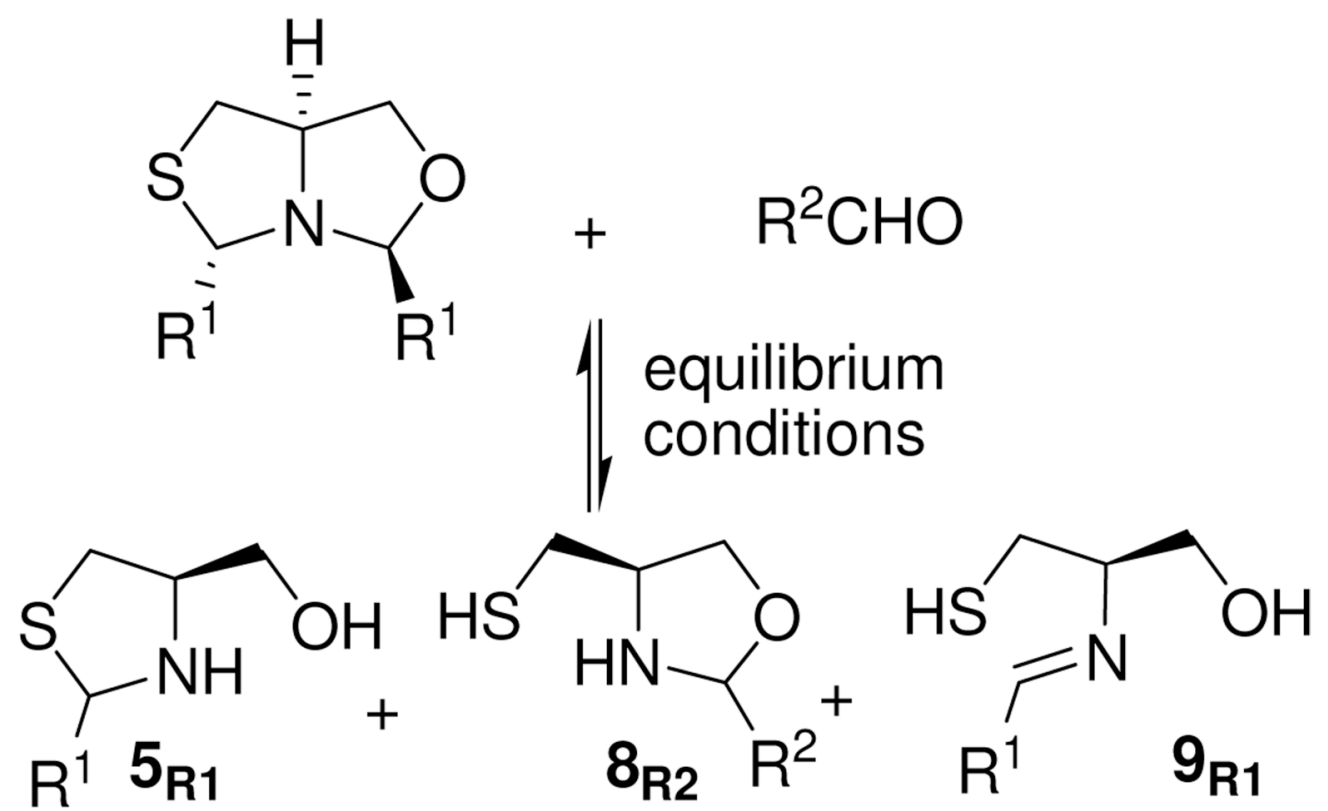<smiles>[R20]C=N[C@@H](CO)CS</smiles>
$\mathrm{R}^{2} \quad \mathbf{5}_{\mathrm{R} 2}$<smiles>[R7]C1SC[C@@H]2CO[C@@H]([R7])N12</smiles>

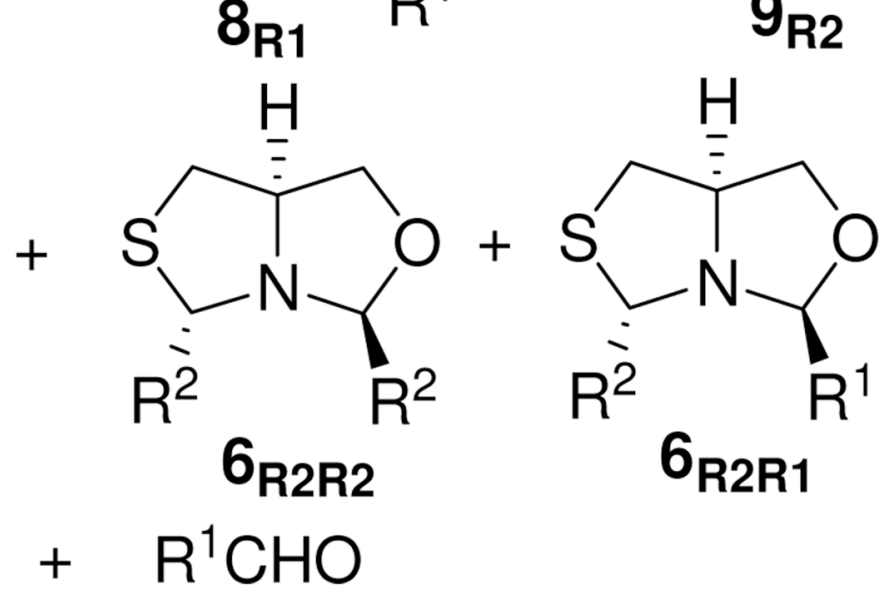

Scheme 5.

Potential library of thiazolidine-oxazolidine heterocycles. 


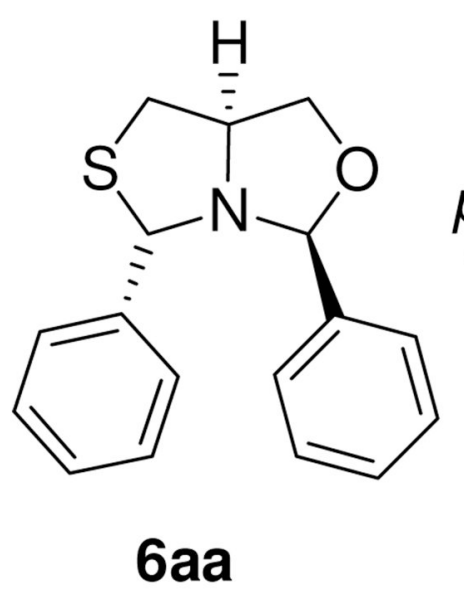

$(55 \%)$

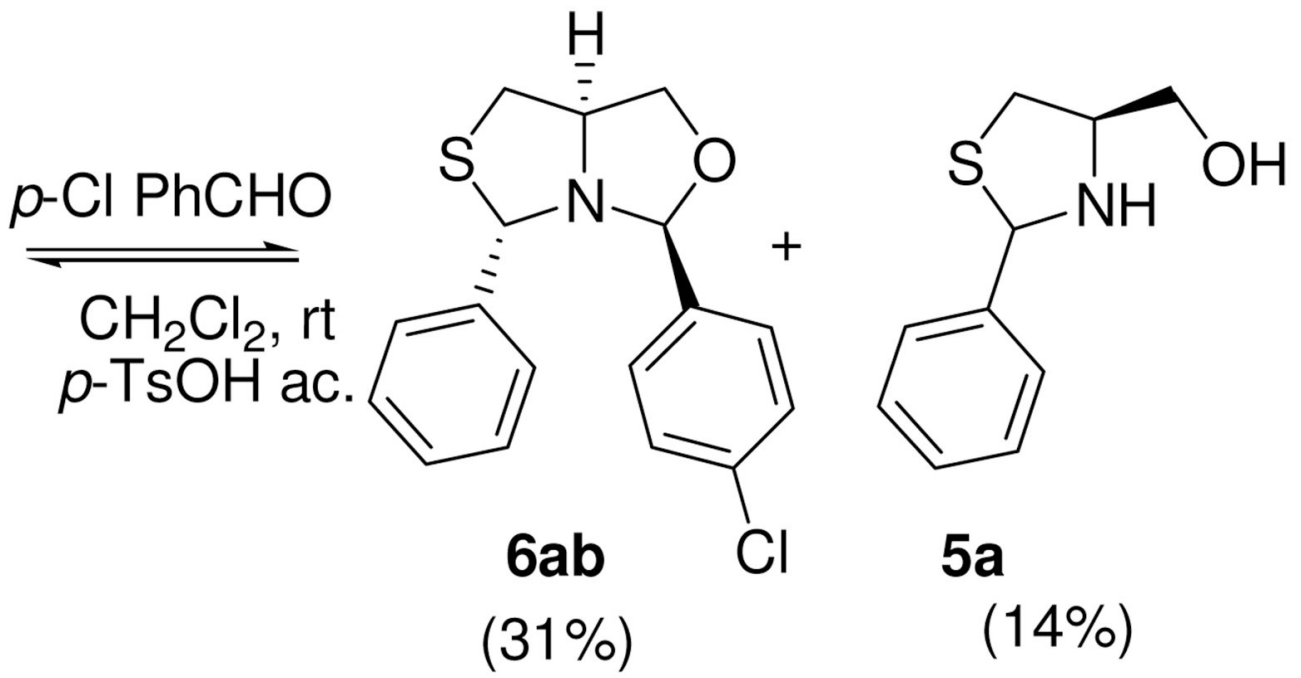

${ }^{a}$ The ratio was established by ${ }^{1} \mathrm{H}$ NMR.

Scheme 6.

Exchange reaction of bicycle 6aa.a

a The ratio was established by ${ }^{1} \mathrm{H}$ NMR. 
Table 1

Optimization of thiazolidine exchange reaction of $\mathbf{3 a}$.

\begin{tabular}{|c|c|c|c|c|}
\hline entry & Reaction conditions $^{a}$ & time (h) & $3 \mathrm{a} / 3 \mathrm{~b}$ ratio $^{b}$ & $2(\%)^{c}$ \\
\hline 1 & $\mathrm{pH} 4, \mathrm{rt}$ & 24 & $45 / 55$ & 3 \\
\hline 2 & $\mathrm{pH} 4, \mathrm{rt}$ & 48 & $44 / 56$ & 2 \\
\hline 3 & $\mathrm{pH} \mathrm{4,} \mathrm{rt}$ & 72 & $46 / 54$ & 10 \\
\hline 4 & $\mathrm{pH} 5, \mathrm{rt}$ & 24 & $71 / 29$ & 5 \\
\hline 5 & $\mathrm{pH} 5$, rt & 48 & $68 / 32$ & 10 \\
\hline 6 & $\mathrm{pH} \mathrm{5,} \mathrm{rt}$ & 72 & $52 / 48$ & 9 \\
\hline 7 & $\mathrm{pH} \mathrm{6,} \mathrm{rt}$ & 24 & $96 / 4$ & 0 \\
\hline 8 & $\mathrm{pH} 6, \mathrm{rt}$ & 48 & $97 / 3$ & 0 \\
\hline 9 & $\mathrm{pH} \mathrm{6,} \mathrm{rt}$ & 72 & $90 / 10$ & 0 \\
\hline 10 & $\mathrm{pH} 7, \mathrm{rt}$ & 72 & $98 / 2$ & 0 \\
\hline 11 & $\mathrm{pH} 4,35^{\circ} \mathrm{C}$ & 24 & $45 / 55$ & $18^{d}$ \\
\hline 12 & $\mathrm{pH} 4,35^{\circ} \mathrm{C}$ & 48 & $35 / 65$ & $16^{e}$ \\
\hline
\end{tabular}

${ }^{a}$ The starting concentration of each component was $1 \mathrm{mM}$; the reaction mixture was stirred in a buffered acetate solution at $\mathrm{pH} 4$ and $\mathrm{pH} 5$, and in a phosphate solution at $\mathrm{pH} 6$ and $\mathrm{pH} 7$.

$b_{\text {The ratio was determined by }}{ }^{1} \mathrm{H}$ NMR.

$c_{\text {The mass balance was quantitative }}$

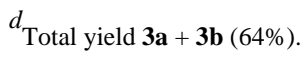

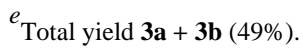


Table 2

Thiazolidine exchange processes starting with $\mathbf{3 b}$ or $\mathbf{3 c}$.

\begin{tabular}{|c|c|c|c|c|}
\hline entry & reaction conditions ${ }^{a}$ & time (h) & $3 \mathrm{~b}: 3 \mathrm{c}$ ratio $b$ & $2(\%)$ \\
\hline 1 & $3 b, 1 c$ & 48 & $25 / 75$ & 4 \\
\hline 2 & $\mathbf{3 c}, \mathbf{1 b}$ & 48 & $24 / 76$ & 3 \\
\hline
\end{tabular}

\footnotetext{
${ }^{a}$ The starting concentration of each component was $1 \mathrm{mM}$, the reaction mixture was stirred at $\mathrm{rt}$ in a buffered acetate solution at $\mathrm{pH} 4$.

${ }^{b}$ The ratio was determined by ${ }^{1} \mathrm{H}$ NMR and confirmed by preparative isolation.
} 